\title{
Imaging markers of disease progression in multiple system atrophy
}

\author{
Beatrice Heim ${ }^{1}$, Florian Krismer ${ }^{1,2}$, Werner Poewe ${ }^{1,2}$ \& Klaus Seppi ${ }^{*, 1,2}$ \\ ${ }^{1}$ Department of Neurology, Medical University Innsbruck, 6020 Innsbruck, Austria \\ ${ }^{2}$ Neuroimaging Research Core Facility, Medical University Innsbruck, 6020 Innsbruck, Austria \\ *Author for correspondence: Tel.: +43 512504 81498; klaus.seppi@tirol-kliniken.at
}

Different neuroimaging modalities hold potential as surrogate markers of underlying neurodegeneration in multiple system atrophy (MSA) and may reflect cell loss, altered glucose metabolism, microglial proliferation, astroglial activation, and nigrostriatal denervation. Multiple studies have demonstrated that serial structural and functional imaging studies are capable of demonstrating neurodegeneration in MSA patients quantitatively, which allows sample size estimates based on rates of progression of these neuroimaging markers. This review summarizes recent research findings as a tool to assess longitudinal changes of serial neuroimaging-derived parameters in MSA.

First draft submitted: 18 December 2018; Accepted for publication: 11 April 2019; Published online: 29 August 2019

Keywords: dopamine transporter single-photon emission computed tomography (DAT-SPECT) • MRI • multiple system atrophy $(\mathrm{MSA}) \bullet$ neuroimaging $\bullet$ positron emission tomography $(\mathrm{PET}) \bullet$ progression

Multiple system atrophy (MSA) is a rare and sporadic neurodegenerative alpha-synucleinopathy with rapid progression of debilitating symptoms and a reduced survival between 6 and 9 years. The clinical presentation is heterogeneous and includes parkinsonian, cerebellar and autonomic symptoms in variable combinations. The overall prevalence of MSA is 4.4/100,000 and the incidence is less than 0.6/100,000/year [1,2].

So far, there is no effective symptomatic therapy for this rapidly and relentlessly progressive disease and, in contrast to Parkinson's disease (PD), sustained improvement of symptoms by means of pharmacological as well as nonpharmacological therapies is rarely achieved $[3,4]$.

Recent advances in understanding the molecular pathogenesis of MSA have revealed novel targets for potentially disease-modifying therapies. Testing any of those new targets for intervention will require outcome measure that are sufficiently sensitive to reflect disease progression over time periods, which could be studied in early-stage clinical development programs. Clinical measures of progression like the Unified Multiple System Atrophy Rating Scale (UMSARS) have indeed shown robust change over 12 months in previous trials [5], but are subject to inter-rater variability and do not directly reflect the underlying neurodegenerative process. Therefore, there is an urgent need for biomarkers that are closely linked to the underlying biology of the disease. Multiple studies have demonstrated that serial structural and functional imaging studies are capable of demonstrating neurodegeneration in MSA patients quantitatively [6]. For this reason, sample size estimates based on rates of progression of an imaging marker progression can be calculated [7].

This review focuses on neuroimaging as a tool to assess longitudinal changes of serial neuroimaging-derived parameters in MSA.

\section{Measuring disease progression with neuroimaging}

Different neuroimaging modalities hold potential as surrogate markers of underlying neurodegeneration and may reflect cell loss, altered glucose metabolism, microglial proliferation, astroglial activation and nigrostriatal denervation. Apart from visual interpretation of structural MRI, postprocessing of MRI sequences enables quantitative evaluation of MSA-specific brain abnormalities [8-10].

Table 1 summarizes neuroimaging markers applied in MSA patients to reflect different features of neurodegeneration. Studies on neuroimaging as a tool to assess longitudinal changes of serial neuroimaging-derived parameters

Future $\because$ Medicine 
Table 1. Neuroimaging markers used in multiple system atrophy progression studies to detect different features of neurodegeneration.

\begin{tabular}{|c|c|c|c|c|}
\hline \multirow[t]{2}{*}{ Imaging marker } & \multicolumn{4}{|c|}{ Neurodegenerative feature } \\
\hline & Neuronal/axonal loss & Myelin disruption & $\begin{array}{l}\text { Microglial activation/ } \\
\text { gliosis }\end{array}$ & Iron content \\
\hline \multicolumn{5}{|c|}{ Radiotracer imaging marker } \\
\hline FDG-PET & $\begin{array}{l}\text { Reduced glucose } \\
\text { metabolism }\end{array}$ & & & \\
\hline DAT-SPECT & Nigrostriatal denervation & & & \\
\hline PK11195-PET & & & Microglial activation & \\
\hline \multicolumn{5}{|l|}{ MRI marker } \\
\hline T1 sequences & $\begin{array}{l}\text { Atrophy; diameter, area, } \\
\text { volumes, automated } \\
\text { volume analysis }\end{array}$ & & & \\
\hline T2 sequences & Atrophy & & Signal increase & Signal decrease; R2 increase \\
\hline Diffusion imaging & $M D, F A, A D, F W$ & $\mathrm{FA}, \mathrm{RD}$ & $\mathrm{MD}, \mathrm{FW}$ & \\
\hline Iron-sensitive sequences & & & & Signal decrease; different metrics ${ }^{\dagger}$ \\
\hline \multicolumn{5}{|c|}{$\begin{array}{l}\text { Qualitative markers in italic and bold; quantitative markers in recte. } \\
\text { † Depending on the sequence (e.g., R2* with T2* or GRE sequences; phase shift values with SWI, iron percentage with SWI, SWI signal intensities). } \\
\text { AD: Axial diffusivity; DAT-SPECT: Dopamine transporter single-photon emission computed tomography; FA: Fractional anisotropy; FDG-PET: 18-F-fluorodeoxyglucose positron } \\
\text { emission tomography; FW: Free water; GRE: Gradient echo sequences; MD: Mean diffusivity; R2: T2 relaxation rate; R2*: T2* relaxation rate; RD: Radial diffusivity; SWI: } \\
\text { Susceptibility-weighted imaging. }\end{array}$} \\
\hline
\end{tabular}

in the MSA were identified by two authors (B Heim, K Seppi) through a systematic PubMed search. The following search terms were used: ('multiple system atrophy' OR MSA OR 'olivopontocerebellar atrophy' OR OPCA OR 'striatonigral degeneration' OR SND OR 'Shy-Drager syndrome') AND ('magnetic resonance imaging' OR MRI OR diffusion* OR diffusivity* OR DWI OR DTI OR volume OR 'magnetic resonance volume*' OR VBR OR 'boundary shift integral' OR BSI OR 'gray matter density' OR 'cortical thickness' OR 'iron*' OR 'single photon emission computed tomography' OR SPECT OR 'positron emission tomography' OR PET OR 'glucose metabolism'). We also checked reference lists from imaging review articles for the search of additional references. The term diffusivity used in this article includes Trace(D), averaged apparent diffusion coefficient and mean diffusivity. Full papers published from March 1986 through 30 November 2018 were considered. Papers had to satisfy the following, predefined eligibility criteria: Papers were required to be published in English language. Patients with MSA were included in the study. Studies were required to report longitudinal changes of serial neuroimaging-derived parameters.

\section{Radiotracer imaging studies}

Serial radiotracer imaging studies were conducted in MSA patients and targeted different neurochemical systems. The most widely commonly used tracers in positron emission tomography (PET) and single-photon emission computed tomography (SPECT) imaging target presynaptic dopamine integrity. One study characterized the progression of dopamine transporter (DAT) decline using $[(123) \mathrm{I}] \beta-\mathrm{CIT}$ in the striatum and extrastriatal regions including the midbrain and pons of patients with the Parkinsonian variant of MSA (MSA-P; see Figure 1) [11].

In this study, a relative decline of tracer uptake at follow-up compared with the baseline scan was evident in the caudate and anterior putamen of MSA-P versus PD. However, no correlations were found between changes in clinical rating scales (Unified Parkinson's Disease Rating Scale [UPDRS] motor score, Hoehn and Yahr [H\&Y] stage or disease duration) and [123I] $\beta$-CIT uptake change over time.

In addition, $\left[{ }^{18} \mathrm{~F}\right]$-fluorodeoxyglucose $\left({ }^{18} \mathrm{~F}\right.$-FDG)-PET has been used to study changes in glucose metabolism and microglial activation was examined using [11C](R)-PK11195-PET and more recently (11)C-PBR28-PET, which measures the expression of the $18 \mathrm{kDa}$ translocator protein (TSPO).

PK11195 PET is an established PET marker of microglial activation, and it has been used as an exploratory outcome measure in a subgroup of participants in the 'Minocycline for MSA' trial (MEMSA-trial, applied in 8 out of 63 randomized patients) [12]. Although the progression of microglial activation in the placebo arm of this trial as assessed with [11C](R)-PK11195-PET revealed heterogeneous pattern of changes in different brain regions, overall there was a significant increase $(0.041 \pm 0.038)$ of the voxel-weighted sum of $[11 \mathrm{C}](\mathrm{R})-\mathrm{PK} 11195$ binding in the placebo arm over the 12 months study period. Intriguingly, there appeared to be attenuated microglial activation 


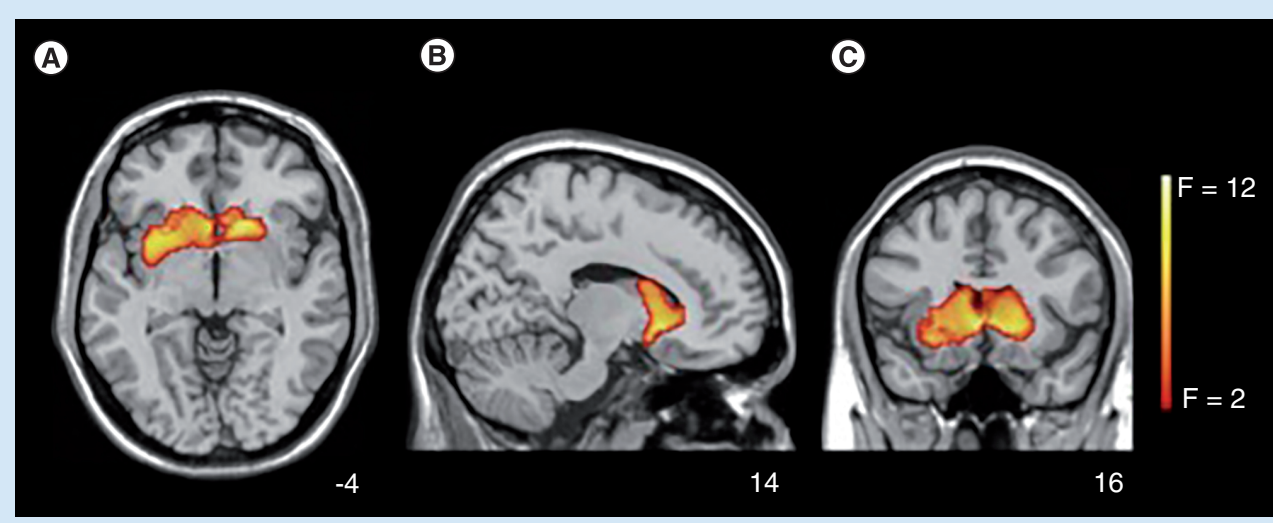

Figure 1. Statistical parametric mapping transverse, sagittal and coronal maximum intensity projection F-maps rendered on to a stereotactically normalized MRI scan, showing within the scan interval areas of significant relative decline in [123I] $\beta$-CIT binding potential values in the caudate and anterior putamen of patients with Parkinsonian variant of multiple system atrophy compared with those with Parkinson's disease, whereas no significant relative signal alteration was observed in the brainstem. Numbers correspond to the $x, y, z$ coordinates in Montreal Neurological Institute space.

Modified with permission from [11].

as assessed with PK11195-PET in the three patients from the minocycline as compared with the five patients from the placebo group.

None of the clinical ratings showed a correlation with PK11195 binding, possibly reflecting the exploratory approach of the imaging substudy in this trial. Another clinical trial assessing effects on microglia activation in the striatum using serial [11C]PBR28-PET in a trial of a myeloperoxidase inhibitor binding to the mitochondrial translocator protein (TSPO) is still in process (https://clinicaltrials.gov/ct2/show/NCT02388295).

Change in cerebral glucose metabolism patterns using ${ }^{18} \mathrm{~F}$-FDG-PET has been studied as a secondary end point in the MSA mesenchymal stem cell trial [13]. The results revealed greater reductions in cerebral glucose metabolism in various brain regions particularly affecting the frontal lobe in the placebo group as compared with the mesenchymal stem cell group. Rates of progression have not been reported in this study and correlation analyses of cerebral glucose metabolism and changes in clinical outcome measures were not assessed in this trial.

\section{MRI studies}

Automated methods for the longitudinal assessment of volumetric MR studies are based on an automated definition of tissue type in each voxel. Voxel-based morphometry (VBM) is applied to groups of scans highlighting atrophy patterns in groups of patients over time. By contrast, methods using registration of serial imaging are applied to individual scan pairs with accurate registration of follow-up and baseline scan, thus determining rates of atrophy rather than atrophy patterns [14].

In one study, VBM was applied to two serial MR images in 14 patients with probable MSA-P and revealed a marked progression of brain atrophy in numerous brain regions including the striatum, midbrain, thalamus and cerebellum, as well as several brain cortical regions (see Figure 2) [15]. To exclude an age effect and demonstrate a more rapid neurodegeneration in MSA as compared with PD, the same VBM approach was applied to an age-matched PD cohort where no progression of brain atrophy was found [15]. Moreover, shorter disease duration correlated with progression of atrophy in the striatum, whereas longer disease duration was correlated with increasing atrophy in the cortical areas and cerebellar hemispheres suggesting that early degeneration of the basal ganglia drives late onset cortical atrophy. However, a correlation between a clinical motor rating scale and brain atrophy could not be established [15].

A further method to measure progression is callosal tissue loss in MSA. Callosal thickness declined over time in MSA in another study using VBM [16]. Changes mainly affected the isthmus of the corpus callosum, reflecting a disease-specific pattern of neurodegeneration and cortical atrophy, fitting well with the predominant impairment of 

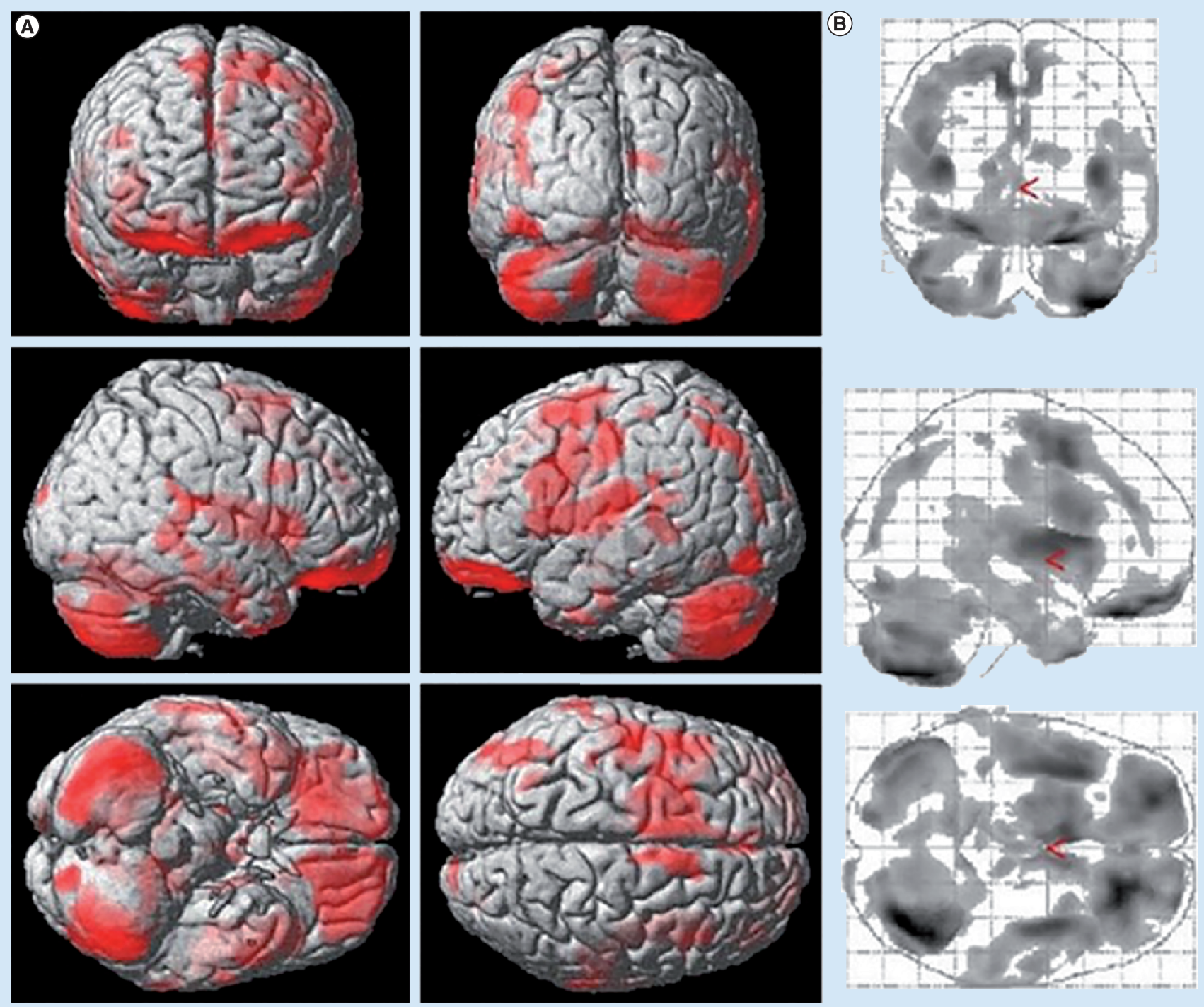

Figure 2. Progression of brain atrophy in Parkinsonian variant of multiple system atrophy in comparison with Parkinson's disease. There was no progression of brain atrophy in the Parkinson's disease cohort and marked progression of brain atrophy in the Parkinsonian variant of multiple system atrophy cohort in regions including the striatum, midbrain, thalamus and cerebellum, as well as cortical regions such as the primary sensorimotor cortex, supplementary motor area, lateral premotor cortex, medial frontal gyrus, middle frontal gyrus, orbitofrontal cortex, insula, posterior parietal cortex and hippocampus (A) overlay onto a rendered brain surface; (B) glass brain view. Modified with permission from [15].

motor functions in MSA. Nevertheless, this study did not assess if VBM changes correlate with clinical parameters over time.

Interestingly, MRI-based morphometry was exploited as a secondary end point in the mesenchymal stem cell trial [13]. The results revealed greater reductions in gray matter density at 360 days relative to baseline in the placebo group. Correlation analyses of gray matter density and clinical outcome measure changes were not assessed in this trial. A post hoc analysis of this trial [17] found more extensive cortical thinning over time in the placebo group affecting the frontal, temporal and parietal areas. Clinicoradiological associations indicated that declines in MoCA scores and phonemic fluency during the follow-up period were significantly correlated with cortical thinning of the frontal and anterior as well as posterior temporal areas in placebo-treated MSA patients. Of note, there were no significant decreases in volumes of caudate, putamen, pallidum and thalamus at 1-year follow-up in any of the treatment groups of this trial. 


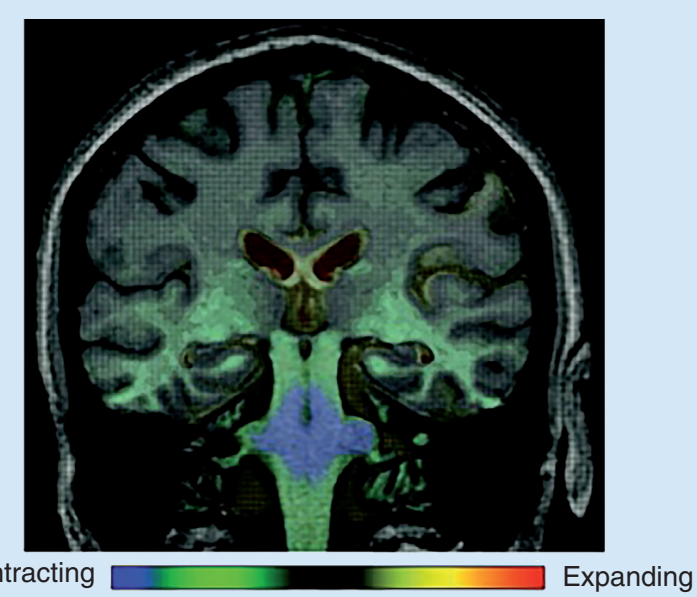

Figure 3. Fluid registration of serial MRI scans was used to demonstrate regional atrophy in one multiple system atrophy patient with subsequently pathological confirmation. This is a coronal MRI scan with voxel-compression-mapping overlay to demonstrate areas undergoing atrophy. The two scans revealed several differences between regions of increasing atrophy: the most prominent atrophy was found to be in the pons and middle cerebellar peduncles, as well as in the midbrain, medulla, vermis, cerebellar white matter, superior and inferior cerebellar peduncles, tegmentum and olives. Moreover, ventricular enlargement is also shown.

Reused with permission from [18].

Imaging studies in patients with postmortem confirmed MSA are sparse. One case report utilizing fluid registration of serial MRI scans demonstrated regional atrophy in a single MSA patient (see Figure 3) [18].

In a study assessing annual whole and regional brain atrophy rates in patients with PD, MSA-P, progressive supranuclear palsy (PSP) and healthy controls $[19,20]$, atrophy rates in MSA-P were greatest in the pons and cerebellum, reaching values of up to $4.5 \% \pm 3.2$ and $3.2 \% \pm 1.9$ atrophy per year. Moreover, regional atrophy rates were significantly higher than whole-brain atrophy rates $(1.0 \% \pm 1.1)$. An increase in motor disability as measured by UPDRS-III was associated with increased rates of pontine atrophy. There was a significant decrease of pontine area in MSA compared with controls in a further study [21]. A more recent study reported somewhat higher annualized whole brain atrophy rates of $1.65 \%( \pm 1.1)$ in a cohort of eight MSA patients [22]. Similar to the former study, no correlations were detected between motor progression and whole-brain atrophy rates [22].

Using diffusion imaging, a significant increase of putaminal diffusivity over time has been demonstrated in two longitudinal studies [23,24], while another study found no increase of putaminal diffusivity over time although putaminal diffusivity was increased at baseline [21]. Methodological reasons might explain this discrepancy: while the putamen was segmented as a whole structure in the former studies [23,24], the latter study measured only two small regions of interest of the putamen [21]. Moreover, in the former studies diffusivity refers to the trace from the diffusion tensor [23,24], while in the latter study diffusivity refers to the apparent diffusion coefficient as measured in the slice direction only [21].

One study compared progression of longitudinal diffusion changes in the basal ganglia of MSA-P versus PD patients revealing a marked increase of putaminal diffusivity over time $\left(0.09 \pm 0.02 \times 10^{-3} \mathrm{~mm}^{2} / \mathrm{s}\right)$ in the MSA-P cohort, which correlated with motor progression as assessed with the UPDRS-III (see Figure 4) [24].

The second serial diffusion imaging study tried to assess the evolution of diffusion properties not only in striatal but also extrastriatal brain regions in seven patients with MSA-P and four patients with MSA with predominantly cerebellar symptoms (MSA-C) [23]. After 1 year, the most prominent increase in diffusivity values was observed in the putamen $(8.8 \pm 5.2 \%)$. Further increases of diffusivity were found in the pons, cerebellar white matter, thalamus and frontal white matter. Percent changes of motor progression as assessed with UPDRS-III and UMSARS and disease duration did not correlate with percent changes of diffusivity in any brain region.

The rasagiline-for-MSA trial (MSA-RAS-202) evaluating a potential disease-modifiying effect of rasagiline in MSA-P patient exploited diffusion-weighted imaging as exploratory outcome in an imaging substudy [25]. The 

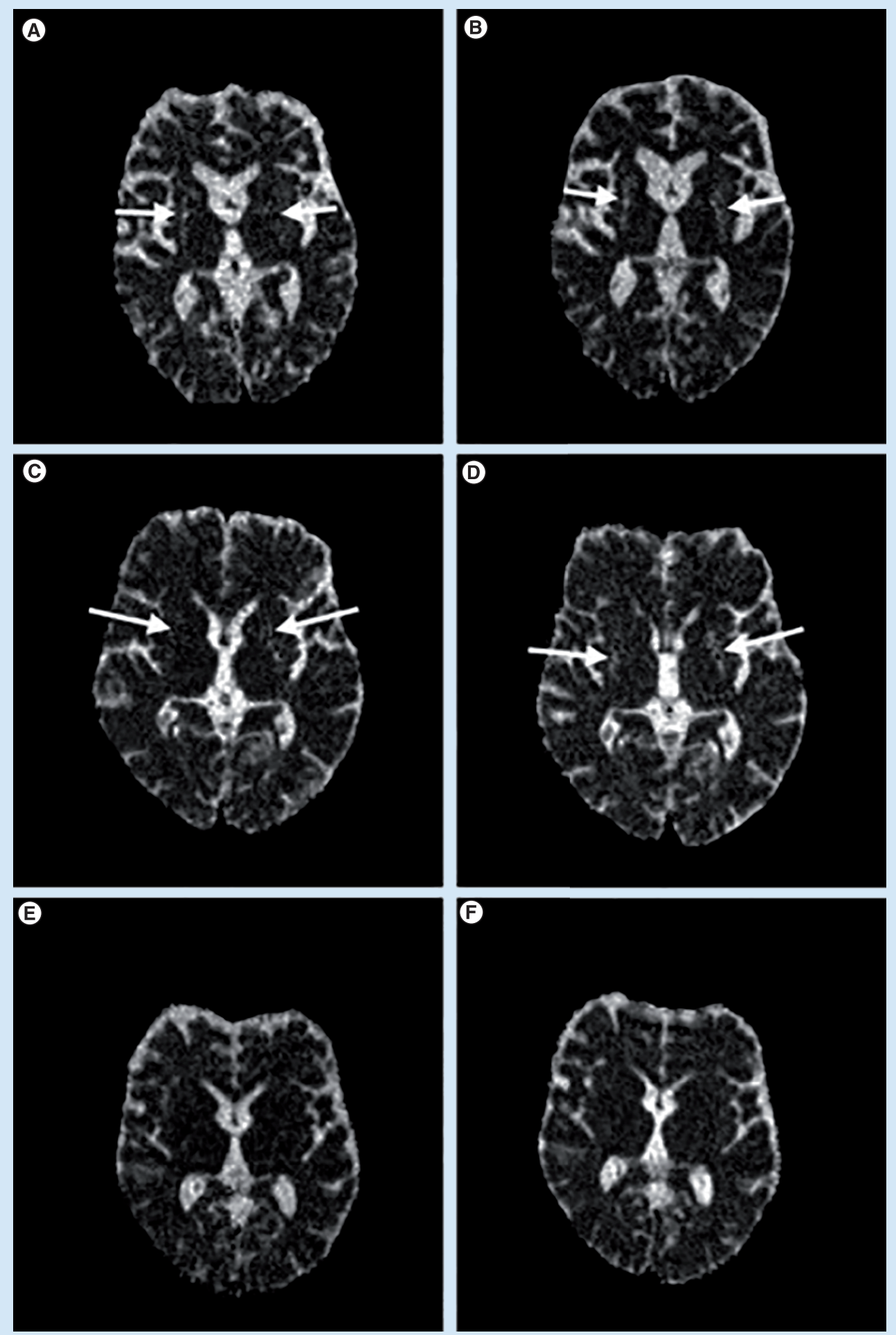

Figure 4. Diffusivity maps at the level of mid-striatum in individual patients with the Parkinson variant of multiple system atrophy. $n=2$; (A) baseline; (B) follow-up in one patient; (C) baseline; (D) follow-up in another patient and Parkinson's disease (E) baseline; (F) follow-up. Note the diffuse hyperintensity - corresponding to increased diffusivity - in the putamina of the patient with Parkinson variant of multiple system atrophy (arrows in A-D), which are increased at follow-up (B \& D) compared with baseline examination (A \& C). The Parkinson's disease patient shows no increased diffusivity in the putamen, neither at baseline (E) nor at follow-up (F). Of the diffusivity changes during follow-up, only putaminal diffusivity increased significantly in the Parkinson variant of multiple system atrophy group, while none of the diffusivity values in the basal ganglia regions in the Parkinson's disease patients changed at follow-up compared with baseline. Moreover, no progression of any putaminal abnormalities was shown using semiquantitative ratings of abnormalities on structural MRI. Modified with permission from [24]. 


\begin{tabular}{|c|c|c|c|c|c|c|c|c|c|c|c|}
\hline \multirow[t]{2}{*}{ Study (year) } & \multicolumn{2}{|c|}{ Cohort characteristics } & \multirow{2}{*}{$\begin{array}{l}\text { Age } \\
\text { Mean } \pm \text { SD }\end{array}$} & \multirow{2}{*}{$\begin{array}{l}\begin{array}{l}\text { Disease } \\
\text { duration }\end{array} \\
\text { Mean } \pm \text { SD }\end{array}$} & \multicolumn{2}{|c|}{ UMSARS-I } & \multicolumn{2}{|c|}{ UMSARS-II } & \multicolumn{2}{|c|}{ UMSARS-total } & \multirow[t]{2}{*}{ Ref. } \\
\hline & Subtype (n) & $\begin{array}{l}\text { Diagnostic } \\
\text { certitude }\end{array}$ & & & Mean \pm SD & $\operatorname{cov}(\%)$ & Mean \pm SD & $\operatorname{cov}(\%)$ & Mean \pm SD & $\operatorname{cov}(\%)$ & \\
\hline $\begin{array}{l}\text { Wenning et al. } \\
\text { (2013) }\end{array}$ & $P>C(85)$ & Prob $>$ poss & $62.1 \pm 7.7$ & $5.5 \pm 3.8$ & $6.5 \pm 6.0$ & 92.3 & $8.2 \pm 7.0$ & 85.4 & $14.6 \pm 11.8$ & 80.8 & [28] \\
\hline $\begin{array}{l}\text { Low et al. } \\
\text { (2015) }\end{array}$ & $P>C(79)$ & Prob & $63.4 \pm 8.6$ & NG & $3.9 \pm 5.8$ & 148.7 & $4.6 \pm 5.0$ & 108.7 & $7.6 \pm 8.4$ & 110.5 & [27] \\
\hline $\begin{array}{l}\text { Matsushima } \\
\text { et al. }(2016)^{\dagger}\end{array}$ & $C>P(63)$ & Prob $>$ poss & $60.0 \pm 8.3$ & $3.8 \pm 2.4$ & ND & 238.6 & ND & 91.6 & ND & ND & [30] \\
\hline $\begin{array}{l}\text { Low et al. } \\
(2014)^{\ddagger}\end{array}$ & $C>P(50)$ & Prob $>$ poss & $61.1 \pm 9.2$ & NG & $5.6 \pm 5.0$ & 89.3 & $5.4 \pm 6.6$ & 122.2 & $10.8 \pm 10.7$ & 99.1 & [29] \\
\hline $\begin{array}{l}\text { Poewe et al. } \\
(2015)^{\ddagger}\end{array}$ & P only (90) & Prob $>$ poss & $65.1 \pm 8.6$ & $3.7 \pm 2.4$ & $4.4 \pm 5.7$ & 129.5 & $3.5 \pm 6.6$ & 188.6 & $7.8 \pm 10.4$ & 133.3 & [4] \\
\hline $\begin{array}{l}{ }^{\dagger} \mathrm{COV} \text { calculated } \\
\ddagger \text { Progression rate } \\
\mathrm{C} \text { : Cerebrellar m }\end{array}$ & $\begin{array}{l}\text { om standardize } \\
\text { refer to Placeb } \\
\text { iple system atr }\end{array}$ & $\begin{array}{l}\text { d response me } \\
\text { orm. }\end{array}$ & (i.e., mean sc & $\begin{array}{l}\text { change divid } \\
\text {; ND: Not de }\end{array}$ & $\begin{array}{l}\text { by the SD of s } \\
\text { nined; NG: Nc }\end{array}$ & $\begin{array}{l}\text { e change) } \\
\text { iven; } P \text { : Pal }\end{array}$ & $\begin{array}{l}\mathrm{n} \text { in the pape } \\
\text { sonian variant }\end{array}$ & $\begin{array}{l}\text { fe., } 100 \% \text { / } \\
\text { f MSA; Pos }\end{array}$ & $\begin{array}{l}\text { ndardized res } \\
\text { ossible; Prob: }\end{array}$ & $\begin{array}{l}\text { se mean). } \\
\text { bable; SD: }\end{array}$ & lard \\
\hline
\end{tabular}

imaging results are consistent with previous diffusion weighted imaging studies, showing increasing putaminal diffusivity values over time and confirmed the clinical impression of lacking treatment effect [25].

A recent post hoc analysis of the MSA-RAS-202 trial showed faster clinical disease progression in MSA-P patients with MSA-specific structural changes on MRI at 1.5 Tesla (such as putaminal atrophy, pontine atrophy, cerebellar atrophy and middle cerebellar peduncle atrophy, presence of a putaminal hyperintense rim, putaminal signal hypointensity and the hot cross bun sign) at baseline during this 48-week study compared with MSA-P patients without these imaging changes at baseline [26], suggesting that MSA-specific structural MRI abnormalities possibly represent a subgroup of MSA-P that is associated with a more rapid disease progression and a worse prognosis. These findings have obvious consequences for future trials in MSA as patients with a faster disease progression will reach milestones earlier - facilitating shorter trial periods, but with the risks of early discontinuation. Intriguingly, this analysis suggests that recruiting patients with MSA-specific structural MRI changes at baseline could reduce the patient number per group by around ninefold compared with those patients without these changes at baseline [26].

\section{Imaging applications to clinical trials}

Thus far, the UMSARS has been the most commonly used outcome measure for multicenter clinical trials in MSA. UMSARS were established. However, UMSARS progression rates showed considerable variability in two independent natural history studies [27,28], as well as in recent trials (Table 2) [25,29], which hamper direct comparisons of interventional trials and power calculations for future trials.

Table 2 summarizes the two large natural history studies, an observational study to test clinical scale for use in clinical trials on MSA as well as the most recent noninvasive interventional trials [25,27-30].

Neuroimaging has become increasingly popular as secondary outcome measure in treatment trials in neurological disorders including Alzheimer's disease, PD, stroke and multiple sclerosis. Validated neuroimaging markers that were shown to be relevant to the pathogenesis and progression of a disease may help in evaluating outcomes in clinical trials. Due to a reduction in observer-dependent biases, neuroimaging markers capturing the progression of neurodegeneration in MSA seem to have lower variability of progression rates (see Table $3 \&$ Figure 5) [5]. This may result in increased statistical power, decreased sample sizes and (possibly) shortening of the duration of the pivotal trials in MSA. Eventually, these markers might be more suitable than the clinical rating scales, especially in proof-of-concept Phase II trials.

Rates of progression derived from longitudinal studies with serial neuroimaging are available for serial DAT SPECT and PK11195 PET as well as for volumetric MRI and diffusion imaging (see Table 3) [11-13,15-17,19,21-24]. Sample size calculations based on annualized brainstem atrophy rates reduced the required cohorts by three- to five-times compared with those based on whole-brain atrophy rates [31]. The smallest sample sizes in MSA-P were achieved using cerebellar and pontine atrophy rates. Sample size estimates were also calculated based on regional brain diffusivity changes over 1 year and suggested that number of MSA patients might be diminished when using regions showing the most significant diffusivity changes, such as putamen and pons rather than others [23]. Using 
Table 3. Measuring disease progression with neuroimaging.

\begin{tabular}{|c|c|c|c|c|c|c|}
\hline \multirow[t]{2}{*}{ Study (year) } & \multirow[t]{2}{*}{ Cohort size } & \multirow{2}{*}{$\begin{array}{l}\text { Interscan time } \\
\text { (years; MSA-cohort) }\end{array}$} & \multirow[t]{2}{*}{ Marker } & \multicolumn{2}{|l|}{ Main results (in MSA) } & \multirow[t]{2}{*}{ Ref. } \\
\hline & & & & Imaging progression & $\begin{array}{l}\text { Progression rate for } \\
\text { MSA (COV) }\end{array}$ & \\
\hline $\begin{array}{l}\text { Nocker et al. } \\
\text { (2012) }\end{array}$ & $\begin{array}{l}P D n=11 / \text { MSA-P } \\
n=7\end{array}$ & $\begin{array}{l}1.1 \pm 0.5 \text { in MSA-P; } \\
1.4 \pm 0.6 \text { in PD }\end{array}$ & DAT-SPECT & $\begin{array}{l}\text { - Compared with PD, a relative decline of } \\
\text { DAT binding was evident in the caudate } \\
\text { and anterior putamen of MSA-P versus PD } \\
\text { - No significant relative signal alteration } \\
\text { was observed in the brainstem } \\
\text { - No correlation of imaging progression } \\
\text { rates with any clinical parameter } \\
\text { (e.g., disease duration, motor progression } \\
\text { as assessed with UPDRS) }\end{array}$ & $\begin{array}{l}\text { - Relative loss of } \\
\text { caudate DAT-binding: } \\
26 \pm 19 \% \text { ( } 73 \%) \\
\text { - Relative loss of } \\
\text { putamen DAT-binding: } \\
17 \pm 18 \% \text { (COV: } \\
106 \%)\end{array}$ & [11] \\
\hline $\begin{array}{l}\text { Dodel et al. } \\
\text { (2010) }\end{array}$ & $\begin{array}{l}\text { MSA-P } n=8: \\
\text { minocycline } n=3 / \\
\text { placebo } n=5\end{array}$ & 0.5 & $\begin{array}{l}{\left[{ }^{11} \mathrm{C}\right](\mathrm{R})-\mathrm{PK} 11195-} \\
\text { PET }\end{array}$ & $\begin{array}{l}\text { - Attenuated microglial activation in } \\
\text { minocycline group compared with placebo } \\
(p=0.07) \\
\text { P PK11195 binding correlated with none of } \\
\text { the clinical ratings }\end{array}$ & $\begin{array}{l}\text { - Significant increase } \\
\text { of the voxel-weighted } \\
\text { sum of } \\
{\left[{ }^{11} \mathrm{C}\right](\mathrm{R})-\mathrm{PK} 11195} \\
\text { binding: } 0.041 \pm 0.038 \text {; } \\
\text { (COV: } 92 \%)\end{array}$ & [12] \\
\hline $\begin{array}{l}\text { Lee et al. } \\
\text { (2012) }\end{array}$ & $\begin{array}{l}\text { MSA-C } n=33: \\
\text { placebo } n=17 / \\
\text { MSC } n=16^{\dagger}\end{array}$ & 1 & {$\left[{ }^{18} \mathrm{~F}\right] \mathrm{FDG}-\mathrm{PET}$} & $\begin{array}{l}\text { - Cerebellar glucose metabolism in } \\
\text { FDG-PET was significantly lower at day } 360 \\
\text { compared with baseline in both groups } \\
\text { - Placebo group showed extensive areas of } \\
\text { reduced glucose metabolism in the } \\
\text { cerebellum and various cortical regions } \\
\text { - Less decreased cerebellar glucose } \\
\text { metabolism in the MSC-treated group }\end{array}$ & •n.a. & [13] \\
\hline $\begin{array}{l}\text { Brenneis et al. } \\
\text { (2007) }\end{array}$ & $\begin{array}{l}P D n=14 / M S A-P \\
n=14\end{array}$ & $\begin{array}{l}1.0 \pm 0.5 \text { in MSA- } P \\
1.4 \pm 0.6 \text { in PD }\end{array}$ & VBM & $\begin{array}{l}\text { - MSA-specific pattern of progression } \\
\text { includes cortical areas as well as subcortical } \\
\text { areas } \\
\text { - Positive correlation between progression } \\
\text { of brain atrophy and disease duration in } \\
\text { several cortical regions } \\
\text { - Negative correlation between } \\
\text { progression of brain atrophy of striatum } \\
\text { and disease duration } \\
\text { - No correlation of brain atrophy in any } \\
\text { region with UPDRS-III scores }\end{array}$ & $\bullet$ n.a. & [15] \\
\hline $\begin{array}{l}\text { Lee et al. } \\
\text { (2012) }\end{array}$ & $\begin{array}{l}\text { MSA-C } n=33: \\
\text { placeboo } n=17 / \text { MSC } \\
n=16^{\dagger}\end{array}$ & 1 & VBM & $\begin{array}{l}\text { - Cerebellar gray matter density was } \\
\text { significantly lower at day } 360 \text { compared } \\
\text { with baseline in both groups } \\
\text { - Placebo group showed extensive areas of } \\
\text { reduced gray matter density in the } \\
\text { cerebellum and various cortical regions } \\
\text { - Less decreased gray matter density in } \\
\text { cerebellum and different cortical areas in } \\
\text { the MSC-treated group }\end{array}$ & - n.a. & [13] \\
\hline $\begin{array}{l}\text { Minnerop } \\
\text { et al. (2010) }\end{array}$ & $\begin{array}{l}\text { MSA-C } n=10 / \\
\text { MSA-P } n=4 / \\
\text { controls } n=14\end{array}$ & $\begin{array}{l}1.2 \pm 0.25 \text { in MSA; } \\
1.4 \pm 0.5 \text { in controls }\end{array}$ & VBM & $\begin{array}{l}\text { - Decline of callosal thickness over time in } \\
\text { MSA, mainly in the isthmus, but not in MSA }\end{array}$ & $\bullet$ n.a. & [16] \\
\hline $\begin{array}{l}\text { Paviour et al. } \\
\text { (2006a) }\end{array}$ & $\begin{array}{l}\mathrm{PSP} n=24 / \mathrm{MSA}-\mathrm{P} \\
\mathrm{n}=11 / \mathrm{PD} \mathrm{n}=12 / \\
\text { controls } \mathrm{n}=18\end{array}$ & $0.7 \pm 0.05$ & BSI & $\begin{array}{l}\text { - Similar atrophy rates in PD and controls } \\
\text { - Greater regional rates of atrophy of } \\
\text { infratentorial structures than whole-brain } \\
\text { rates of atrophy in both PSP and MSA-P } \\
\text { - Increase in the UPDRS-III was associated } \\
\text { with increased rates of pontine atrophy } \\
\text { - Increased rates of pontine, cerebellar, } \\
\text { midbrain and whole-brain atrophy rates } \\
\text { were associated with different } \\
\text { neuropsychological outcome measures }\end{array}$ & $\begin{array}{l}\text { - Annualized whole } \\
\text { brain atrophy rate } \\
1.0 \% \pm 1.1 \text { (COV: } \\
110 \%) \\
\text { - Annualized pontine } \\
\text { atrophy rate } \\
4.5 \% \pm 3.2(\mathrm{COV}: 71 \%) \\
\text { - Annualized } \\
\text { cerebellar atrophy rate } \\
3.2 \% \pm 1.9 \text { (COV: } 59 \%)\end{array}$ & [19] \\
\hline $\begin{array}{l}\text { Guevara et al. } \\
\text { (2016) }\end{array}$ & $\begin{array}{l}\text { Controls } n=10 / \text { PD } \\
n=20 / \text { PSP } n=12 / \\
\text { MSA } n=8\end{array}$ & $1.03 \pm 0.08$ & $\begin{array}{l}\text { Volumetric MRI } \\
\text { technique (SIENA) }\end{array}$ & $\begin{array}{l}\text { - Similar whole brain atrophy rates in PD } \\
\text { and controls } \\
\text { - Greater whole brain atrophy rates in both } \\
\text { PSP and MSA } \\
\text { - No significant correlations were found } \\
\text { between annual whole brain atrophy rates } \\
\text { and annualized clinical assessments (UPDRS } \\
\text { III, H\&Y and CGI-S) }\end{array}$ & $\begin{array}{l}\text { - Annualized whole } \\
\text { brain atrophy rates: } \\
1.65 \% \pm 1.1 \text { (COV: } \\
66.7 \%)\end{array}$ & [22] \\
\hline
\end{tabular}

\footnotetext{
†Same patient cohorts.
}

$¥$ In this study, diffusivity refers to the ADCs, which were measured in the slice direction only.

ADC: Apparent diffusion coefficient; BSI: Boundary shift integral; COV: Coefficient of variation; DAT-SPECT: Dopamine transporter single-photon emission computed tomography; DWI: Diffusion weighted imaging; FDG-PET: 18-F-fluorodeoxyglucose positron emission tomography; GRE: Gradient echo imaging; H\&Y: Hoehn and Yahr; MSA-C: Cerebellar variant of MSA; MSA-P: Parkinsonian variant of MSA; MSC: Mesenchymal stem cells; n: Number; n.d.: Not determined; n.a.: Not applicable; PD: Parkinson's disease; PSP: Progressive supranuclear palsy; SMA: Supplementary motor area; UPDRS: Unified Parkinson's Disease Rating Scale; UMSARS: Unified Multiple System Atrophy Rating Scale; VBM: Voxel-based morphometry. 
Table 3. Measuring disease progression with neuroimaging (cont.).

\begin{tabular}{|c|c|c|c|c|c|c|}
\hline \multirow[t]{2}{*}{ Study (year) } & \multirow[t]{2}{*}{ Cohort size } & \multirow{2}{*}{$\begin{array}{l}\text { Interscan time } \\
\text { (years; MSA-cohort) }\end{array}$} & \multirow[t]{2}{*}{ Marker } & \multicolumn{2}{|l|}{ Main results (in MSA) } & \multirow[t]{2}{*}{ Ref. } \\
\hline & & & & Imaging progression & $\begin{array}{l}\text { Progression rate for } \\
\text { MSA (COV) }\end{array}$ & \\
\hline $\begin{array}{l}\text { Sunwoo et al. } \\
\text { (2014) }\end{array}$ & $\begin{array}{l}\text { MSA-C } n=26: \\
\text { placebo } n=15 / \text { MSC } \\
n=11^{\dagger}\end{array}$ & 1 & $\begin{array}{l}\text { Automated } \\
\text { volumetric analysis }\end{array}$ & $\begin{array}{l}\text { - Significant decrease of volumes of } \\
\text { caudate, putamen, pallidum and thalamus } \\
\text { at } 1 \text {-year follow-up } \\
\text { - No significant difference in subcortical } \\
\text { deep gray matter volumes of caudate, } \\
\text { putamen and thalamus between the } \\
\text { groups } \\
\text { - Cortical thinning in the placebo group } \\
\text { was more extensive } \\
\text { - Declines in MoCA scores and phonemic } \\
\text { fluency during the follow-up period were } \\
\text { significantly correlated with cortical } \\
\text { thinning of the frontal and posterior } \\
\text { temporal areas and anterior temporal } \\
\text { areas in the placebo group only }\end{array}$ & $\begin{array}{l}\text { - Longitudinal change } \\
\text { of putaminal volume in } \\
\text { placebo arm: } \\
378.20 \pm 216.43 \mathrm{~mm}^{3} \text {; } \\
\text { lowest COV compared } \\
\text { with longitudinal } \\
\text { change of other } \\
\text { subcortical deep gray } \\
\text { matter volumes (COV: } \\
57 \% \text { ) }\end{array}$ & [17] \\
\hline $\begin{array}{l}\text { Reginold et al. } \\
\text { (2014) }\end{array}$ & $\begin{array}{l}\text { MSA-P } n=12 / \text { PSP } \\
n=6 / \text { controls } \\
n=18\end{array}$ & $\begin{array}{l}2.3 \pm 1.4 \text { in MSA-P; } \\
1.6 \pm 0.5 \text { in controls }\end{array}$ & $\begin{array}{l}\mathrm{DWI}^{\ddagger}, \mathrm{GRE}, \\
\text { planimetry }\end{array}$ & $\begin{array}{l}\text { - No change over time in GRE and } \\
\text { diffusivity measures (putamen, pons, MCP) } \\
\text { in MSA-P } \\
\text { - Significant decrease of midsagittal } \\
\text { pontine area in MSA-P } \\
\text { - No change over time in other planimetric } \\
\text { measures (putamen, lateral ventricle, } \\
\text { caudate, MCP, midbrain) } \\
\text { - Increase of UPDRS-III values correlated } \\
\text { with increase of diffusivity in the MCP over } \\
\text { time in MSA-P }\end{array}$ & $\begin{array}{l}\text { - Longitudinal } \\
\text { decrease of pontine } \\
\text { area (over } 2 \text { years of } \\
\text { follow-up): } 0.53 \pm 0.33 \\
\left.\mathrm{~cm}^{2} \text { (COV: } 62 \%\right)\end{array}$ & [21] \\
\hline $\begin{array}{l}\text { Seppi et al. } \\
\text { (2006) }\end{array}$ & $\begin{array}{l}\text { MSA-P } n=10 / P D \\
n=10\end{array}$ & $\begin{array}{l}1.3 \pm 0.5 \text { in MSA-P, } \\
1.2 \pm 0.6 \text { in PD }\end{array}$ & DWI & $\begin{array}{l}\text { - Longitudinal diffusion changes in the } \\
\text { basal ganglia of MSA-P versus PD revealed } \\
\text { a significant increase of putaminal } \\
\text { diffusivity over time in MSA-P } \\
\text { - Putaminal diffusivity change in MSA-P } \\
\text { correlated with motor progression assessed } \\
\text { by the UPDRS }\end{array}$ & $\begin{array}{l}\text { - Increase of putaminal } \\
\text { diffusivity: } \\
0.09 \pm 0.02 \times 10^{-3} \mathrm{~mm}^{2} / \mathrm{s} \\
\text { (COV: } 26 \%)\end{array}$ & [24] \\
\hline $\begin{array}{l}\text { Pellecchia } \\
\text { et al. (2011) }\end{array}$ & $\begin{array}{l}\text { MSA-P } n=7 / \\
\text { MSA-C } n=4\end{array}$ & $1.0 \pm 0.25$ & DWI & $\begin{array}{l}\text { - Most prominent increase in diffusivity } \\
\text { values in the putamen } \\
\text { - Increases of diffusivity over time in the } \\
\text { pons, cerebellar white matter, thalamus } \\
\text { and frontal white matter } \\
\text { - UPDRS III and UMSARS II did not correlate } \\
\text { with percent changes of Trace (D) values in } \\
\text { any brain region }\end{array}$ & $\begin{array}{l}\text { - Relative increase of } \\
\text { putaminal diffusivity: } \\
8.8 \% \pm 5.2 \% \text { (COV: } \\
59 \% \text { ) }\end{array}$ & [23] \\
\hline \multicolumn{7}{|c|}{$\begin{array}{l}\text { †Same patient cohorts. } \\
\text { ¥In this study, diffusivity refers to the ADCS, which were measured in the slice direction only. } \\
\text { ADC: Apparent diffusion coefficient; BSI: Boundary shift integral; COV: Coefficient of variation; DAT-SPECT: Dopamine transporter single-photon emission computed tomography; } \\
\text { DWI: Diffusion weighted imaging; FDG-PET: 18-F-fluorodeoxyglucose positron emission tomography; GRE: Gradient echo imaging; H\&Y: Hoehn and Yahr; MSA-C: Cerebellar } \\
\text { variant of MSA; MSA-P: Parkinsonian variant of MSA; MSC: Mesenchymal stem cells; n: Number; n.d.: Not determined; n.a.: Not applicable; PD: Parkinson's disease; PSP: Progressive } \\
\text { supranuclear palsy; SMA: Supplementary motor area; UPDRS: Unified Parkinson's Disease Rating Scale; UMSARS: Unified Multiple System Atrophy Rating Scale; VBM: Voxel-based } \\
\text { morphometry. }\end{array}$} \\
\hline
\end{tabular}

relative loss of caudate and putaminal DAT binding over about 1 year, sample size estimates were calculated [11]. The smallest sample sizes in MSA were achieved using relative loss of caudate DAT binding.

Generally, sample size estimates for neuroimaging-derived rates of progression depend not only on the mean rate of progression but also on its standard deviation (SD).

The coefficient of variation is a dimensionless number that quantifies the degree of variability relative to the mean defined as the ratio of the SD to the mean as the SD of data must always be understood in the mean context of the data [32]. An increase of the coefficient of variation means that the degree of variability relative to the mean increases. As such, sample sizes increase with increasing coefficient of variation. Table 3 gives all coefficients of variation of the neuroimaging-derived rates of progression.

Figure 5 demonstrates sample size estimates based on established progression rates of clinical and neuroimaging markers with identical requirements for the power calculation of the different markers [11,12,17,20,22-25,28,33]. 


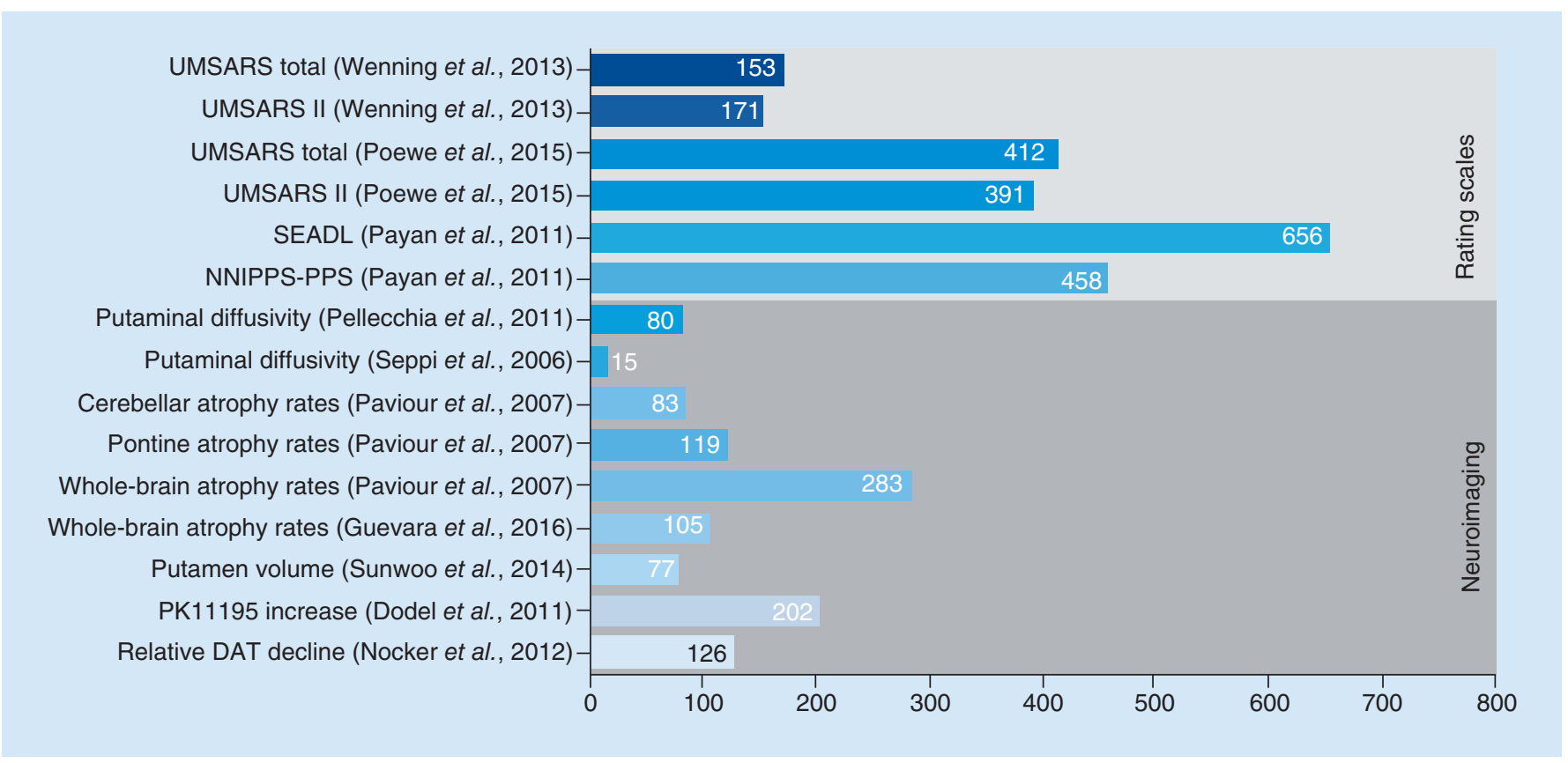

Figure 5. Sample size estimates based on established progression rates of clinical and neuroimaging markers. This bar graph illustrates the number of patients per group needed in a parallel-group design trial to detect the effect of a drug with an anticipated ability to reduce the rate of progression of the clinical or neuroimaging marker by $30 \%$ over 1 year with a power of $90 \%$.

DAT: Dopamine transporter; NNIPPS-PPS: Natural History and Neuroprotection in Parkinson plus syndrome: Parkinson Plus Scale; SEADL: Schwab and England Activity Daily Living scale; UMSARS: Unified multiple system atrophy rating scale.

Modified with permission from [5].

The bar graphs illustrate the number of patients needed in a trial, to detect the effect of a drug with an anticipated ability to reduce the rate of progression of the clinical or neuroimaging marker by $30 \%$ over 1 year with a power of $90 \%$.

\section{Conclusion \& future perspective}

Over the last decade, neuroimaging has become an interesting tool to study progression of neurodegeneration in vivo in MSA. All of these neuroimaging markers (see Table 3) seem to progress more markedly than clinical progression as assessed with clinical rating scales. Moreover, several trials have included neuroimaging as a secondary or exploratory tool clearly demonstrating the capability of neuroimaging as biomarker of progression in MSA. Mainly putaminal or pontine MR markers seem to best capture disease progression as assessed with neuroimaging. Decline of DAT binding in the anterior striatum [11] and brain microglial activation assessed with PK11195-PET [12] are both sensitive to change over time in MSA-P. Moreover, MSA-C-specific progression pattern of cerebral glucose metabolism includes the cerebellum and different cortical areas [13]. Regional rates of atrophy of infratentorial structures (pons and cerebellum) are sensitive to change over time in MSA-P [31], while whole-brain atrophy rate seems to be sensitive to change over time in earlier disease stages only [22]. On the other hand, MSA-P-specific progression-pattern includes different cortical and subcortical areas [15], while MSA-C-specific progression-pattern includes the cerebellum and different cortical areas [13]. Moreover, abnormal diffusivity in the putamen is sensitive to change over time in MSA [23,24]. Incorporating structural MR imaging into a trial design will not only offer a quantitative measure to show an effect on underlying disease but will also reduce the numbers of patients required to show an effect on clinical end points [26]. Significant clinicoradiological associations of some of volumetric imaging markers suggest these markers have potential as markers of disease progression in trials of novel therapies. On the other hand, neither decline of DAT binding in the anterior striatum nor PK11195-binding were associated with motor progression in MSA, and discrepant results have been reported for the association of progression of putaminal diffusivity with motor disability. There are several reasons for the failure to show significant associations between imaging and clinical progression indices. 
First, most of the studies have been performed in small groups of patients with the risk of inadequate power for the assessment of clinicoimaging associations. Second, some of the studies included MSA patients of one of the two subtypes only, while others included mixed MSA populations including both MSA-P and MSA-C patients, which might result in a lower sensitivity for evaluating the heterogenous motor presentation in patient presenting both extrapyramidal and cerebellar disturbances. Third, misdiagnosis in some of the clinically diagnosed patients cannot be excluded in the absence of postmortem verification, particularly in those in early stages of their disease, in which clinical misclassification of Parkinsonian syndromes may occur in up to one quarter of cases even in the hands of experienced neurologists [8].

Finally, even though progression of an imaging marker can be detected in MSA, the same imaging marker might not be suitable to be associated with clinical progression. Indeed, MSA is a multisystem disorder, where progression of one system assessed with a specific imaging marker might not explain the overall clinical progression.

In summary, recent longitudinal studies showed that the different neuroimaging methods summarized in this review have the potential to track disease progression in MSA. Based on current available evidence, the most promising neuroimaging biomarker to assess progression in MSA is the assessment of putaminal diffusivity longitudinally. Future research will reveal the best neuroimaging method or methods for application in MSA clinical trials. Attempts to develop aSYN-PET ligands for alpha synucleinopathies such as MSA are underway, and their availability may mark a further turning point [3].

Executive summary

Background

- There is an urgent need for biomarkers that are closely linked to the underlying biology of multiple system atrophy (MSA).

- Multiple studies have demonstrated that serial structural and functional imaging studies are capable of demonstrating neurodegeneration in MSA patients quantitatively.

Measuring disease progression with neuroimaging

- Studies on neuroimaging as a tool to assess longitudinal changes of serial neuroimaging-derived parameters in the MSA were identified through a systematic PubMed search and through checking reference lists from imaging review articles for the search of additional references.

Radiotracer imaging studies

- Dopamine transporter-binding decline in the anterior striatum and microglial activation assessed with PK11195-PET are both sensitive to change over time in Parkinsonian variant of MSA (MSA-P).

- MSA-C-specific progression pattern of cerebral glucose metabolism includes the cerebellum and different cortical areas.

MRI studies

- Regional atrophy rates of infratentorial structures (pons, cerebellum) are sensitive to change over time in MSA-P, while whole-brain atrophy rate seems to be sensitive to change over time in earlier disease stages only.

- MSA-P-specific progression pattern includes different cortical and subcortical areas, while a MSA-C-specific progression pattern includes the cerebellum and different cortical areas.

- Abnormal putaminal diffusivity is sensitive to change over time in MSA.

Imaging applications to clinical trials

- Number of patients needed to detect a drug effect with an anticipated ability to reduce the progression rate of neuroimaging marker by $30 \%$ over 1 year with a power of $90 \%$ ranges between 80 and 283 depending on the imaging marker used compared with 171-391 patients needed using clinical markers.

- Incorporating structural MRI into a trial design will reduce the numbers of patients required to show an effect on clinical end points.

Summary \& future perspective

- Recent longitudinal studies showed that different neuroimaging methods have the potential to track disease progression in MSA.

- Future research will reveal the best neuroimaging method or methods for application in MSA clinical trials.

\section{Authors' contributions}

K Seppi reviewed conception, organization and execution, contributed to the drafting the manuscript, critical revision of the manuscript and literature search. B Heim contributed to the organization and execution, drafting the manuscript, critical revision of the manuscript and literature search. F Krismer contributed to the organization and execution, critical revision of the manuscript and literature search. W Poewe reviewed conception and organization and contributed to the critical revision of the manuscript. 
Financial \& competing interests disclosure

K Seppi reports personal fees from Teva, UCB, Lundbeck, AOP Orphan Pharmaceuticals AG, Roche, Grünenthal and Abbvie, honoraria from the International Parkinson and Movement Disorders Society, research grants from FWF Austrian Science Fund, Michael J Fox Foundation and International Parkinson and Movement Disorder Society, outside the submitted work. W Poewe received personal fees from Abbvie, Allergan, AstraZeneca, BIAL, Boehringer-Ingelheim, Boston Scientific, GlaxoSmithKline, Ipsen, Lundbeck, Medtronic, MSD, Merck-Serono, Merz, Novartis, Orion Pharma, Teva, UCB and Zambon and received royalties from Wiley Blackwell, Oxford University Press and Cambridge University Press. This work was supported by MSA Coalition (FK JAP GKW HK KS; https://www.multiplesystematrophy.org). The funders had no role in study design, data collection and analysis, decision to publish or preparation of the manuscript. The authors have no other relevant affiliations or financial involvement with any organization or entity with a financial interest in or financial conflict with the subject matter or materials discussed in the manuscript. This includes employment, consultancies, honoraria, stock ownership or options, expert testimony, grants or patents received or pending, or royalties.

No writing assistance was utilized in the production of this manuscript.

\section{Open access}

This work is licensed under the Attribution-NonCommercial-NoDerivatives 4.0 Unported License. To view a copy of this license, visit http://creativecommons.org/licenses/by-nc-nd/4.0/

\section{References}

Papers of special note have been highlighted as: $\bullet$ of interest

1. Bower JH, Maraganore DM, McDonnell SK, Rocca WA. Incidence of progressive supranuclear palsy and multiple system atrophy in Olmsted County, Minnesota, 1976 to 1990. Neurology 49(5), 1284-1288 (1997).

2. Schrag A, Ben-Shlomo Y, Quinn NP. Prevalence of progressive supranuclear palsy and multiple system atrophy: a cross-sectional study Lancet 354(9192), 1771-1775 (1999).

3. Krismer F, Wenning GK. Multiple system atrophy: insights into a rare and debilitating movement disorder. Nat. Rev. Neurol. 13(4), 232-243 (2017).

- This is a state-of-the-art review on multiple system atrophy (MSA).

4. Poewe W, Mahlknecht P, Krismer F. Therapeutic advances in multiple system atrophy and progressive supranuclear palsy. Mov. Disord. 30(11), 1528-1538 (2015).

- This review provides an outlook on emerging targets for future therapies of MSA.

5. Krismer F, Seppi K, Stefanova N, Wenning GK. Toward disease modification in multiple system atrophy: pitfalls, bottlenecks, and possible remedies. Mov. Disord. 31(2), 235-240 (2016).

6. Heim B, Krismer F, Seppi K. Structural imaging in atypical Parkinsonism. Int. Rev. Neurobiol. 142, 67-148 (2018).

- Provides a state-of-the-art review on structural neuroimaging in MSA.

7. Heim B, Krismer F, De Marzi R, Seppi K. Magnetic resonance imaging for the diagnosis of Parkinson's disease. J. Neural. Transm. (Vienna) 124(8), 915-964 (2017).

8. Mahlknecht P, Hotter A, Hussl A, Esterhammer R, Schocke M, Seppi K. Significance of MRI in diagnosis and differential diagnosis of Parkinson's disease. Neurodegener. Dis. 7(5), 300-318 (2010).

9. Rizzo G, Zanigni S, De Blasi R et al. Brain MR contribution to the differential diagnosis of Parkinsonian syndromes: an update. Parkinsons Dis. 2983638 (2016).

10. Stoessl AJ, Lehericy S, Strafella AP. Imaging insights into basal ganglia function, Parkinson's disease, and dystonia. Lancet 384(9942), 532-544 (2014).

11. Nocker M, Seppi K, Donnemiller E et al. Progression of dopamine transporter decline in patients with the Parkinson variant of multiple system atrophy: a voxel-based analysis of [123I]beta-CIT SPECT. Eur. J. Nucl. Med. Mol. Imaging 39(6), 1012-1020 (2012).

12. Dodel R, Spottke A, Gerhard A et al. Minocycline 1-year therapy in multiple-system-atrophy: effect on clinical symptoms and [(11)C] (R)-PK11195 PET (MEMSA-trial). Mov. Disord. 25(1), 97-107 (2010).

13. Lee PH, Lee JE, Kim HS et al. A randomized trial of mesenchymal stem cells in multiple system atrophy. Ann. Neurol. 72(1), 32-40 (2012).

14. Wild EJ, Fox NC. Serial volumetric MRI in Parkinsonian disorders. Mov. Disord. 24(Suppl 2), S691-S698 (2009).

15. Brenneis C, Egger K, Scherfler C et al. Progression of brain atrophy in multiple system atrophy. A longitudinal VBM study. J. Neurol. 254(2), 191-196 (2007).

16. Minnerop M, Luders E, Specht K et al. Callosal tissue loss in multiple system atrophy - a one-year follow-up study. Mov. Disord. 25(15), 2613-2620 (2010). 
17. Sunwoo MK, Yun HJ, Song SK et al. Mesenchymal stem cells can modulate longitudinal changes in cortical thickness and its related cognitive decline in patients with multiple system atrophy. Front. Aging Neurosci. 6, 118 (2014).

18. Schott JM, Simon JE, Fox NC et al. Delineating the sites and progression of in vivo atrophy in multiple system atrophy using fluid-registered MRI. Mov. Disord. 18(8), 955-958 (2003).

19. Paviour DC, Price SL, Jahanshahi M, Lees AJ, Fox NC. Longitudinal MRI in progressive supranuclear palsy and multiple system atrophy: rates and regions of atrophy. Brain 129(Pt 4), 1040-1049 (2006a).

20. Paviour DC, Price SL, Lees AJ, Fox NC. MRI derived brain atrophy in PSP and MSA-P. Determining sample size to detect treatment effects. J. Neurol. 254(4), 478-481 (2007).

21. Reginold W, Lang AE, Marras C, Heyn C, Alharbi M, Mikulis DJ. Longitudinal quantitative MRI in multiple system atrophy and progressive supranuclear palsy. Parkinsonism Relat. Disord. 20(2), 222-225 (2014).

22. Guevara C, Bulatova K, Barker GJ, Gonzalez G, Crossley N, Kempton MJ. Whole-brain atrophy rate in idiopathic Parkinson's disease, multiple system atrophy, and progressive supranuclear palsy. Parkinsons Dis. 2016, 9631041 (2016).

23. Pellecchia MT, Barone P, Vicidomini C et al. Progression of striatal and extrastriatal degeneration in multiple system atrophy: a longitudinal diffusion-weighted MR study. Mov. Disord. 26(7), 1303-1309 (2011).

24. Seppi K, Schocke MF, Mair KJ et al. Progression of putaminal degeneration in multiple system atrophy: a serial diffusion MR study. Neuroimage 31(1), 240-245 (2006).

25. Poewe W, Seppi K, Fitzer-Attas CJ et al. Efficacy of rasagiline in patients with the parkinsonian variant of multiple system atrophy: a randomised, placebo-controlled trial. Lancet Neurol. 14(2), 145-152 (2015).

26. Krismer F, Seppi K, Wenning GK et al. Abnormalities on structural MRI associate with faster disease progression in multiple system atrophy. Parkinsonism Relat. Disord. 58, 23-27 (2018).

27. Low PA, Reich SG, Jankovic J et al. Natural history of multiple system atrophy in the USA: a prospective cohort study. Lancet Neurol. 14(7), 710-719 (2015).

28. Wenning GK, Geser F, Krismer F et al. The natural history of multiple system atrophy: a prospective European cohort study. Lancet Neurol. 12(3), 264-274 (2013).

29. Low PA, Robertson D, Gilman $S$ et al. Efficacy and safety of rifampicin for multiple system atrophy: a randomised, double-blind, placebo-controlled trial. Lancet Neurol. 13(3), 268-275 (2014).

30. Matsushima M, Yabe I, Oba K et al. Comparison of different symptom assessment scales for multiple system atrophy. Cerebellum 15(2), 190-200 (2016)

31. Paviour DC, Price SL, Jahanshahi M, Lees AJ, Fox NC. Regional brain volumes distinguish PSP, MSA-P, and PD: MRI-based clinico-radiological correlations. Mov. Disord. 21(7), 989-996 (2006b).

32. Van Belle G, Martin DC. Sample size as a function of coefficient of variation and ratio of means. Am. Stat. (47)3, 165-167 (1993).

33. Payan CA, Viallet F, Landwehrmeyer BG et al. Disease severity and progression in progressive supranuclear palsy and multiple system atrophy: validation of the NNIPPS - Parkinson Plus Scale. PLoS ONE 6(8), e22293 (2011). 